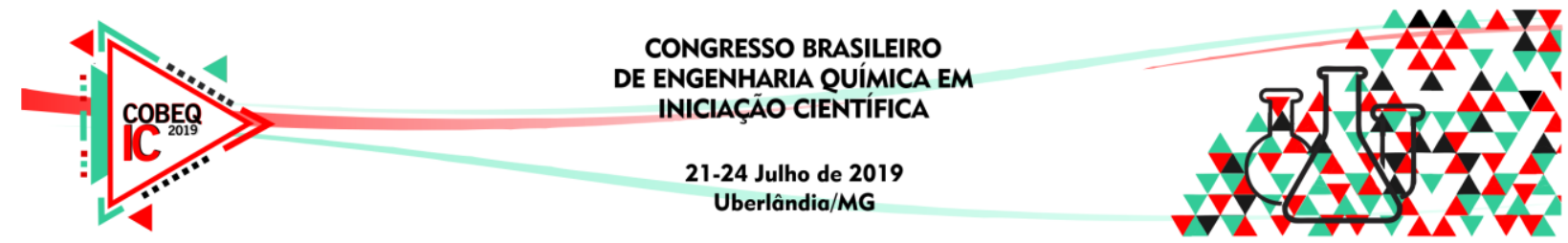

\title{
UTILIZAÇÃO DO RESÍDUO DA ERVA MATE E POLIPROPILENO RECICLADO PARA A PRODUÇÃO DE COMPÓSITOS POLIMÉRICOS
}

\author{
K.S.SANTOS ${ }^{1}$ e A. R SENA NETO ${ }^{1}$ \\ ${ }^{1}$ Universidade Federal de Lavras, Departamento de Engenharia \\ E-mail para contato: karolayne.santos2@estudante.ufla.br
}

\begin{abstract}
RESUMO - A comunidade científica tem estudado a possibilidade de utilização de fibras vegetais como reforço em matrizes poliméricas, com o intuito de produzir novos compósitos sustentáveis e com propriedades mecânicas promissoras. De encontro a essa ideia, o objetivo deste trabalho foi utilizar o resíduo da erva mate como reforço mecânico em uma matriz de polipropileno reciclado. Foram elaborados cinco formulações de compósitos poliméricos com porcentagens distintas de fibra vegetal: PPP, PP10\%, PP20\%, PP30\% e PPC $20 \%$. Estas formulações foram processadas na extrusora com o objetivo de produzir filamentos do compósito. Após a extrusão e peletização, os grânulos foram fundidos na termoprensa com o auxílio de moldes apropriados para obtenção de corpos de prova de flexão e de tração. Com o término deste processo, determinados lotes dos corpos de prova foram submetidos a tratamentos de biodegradação e fotodegradação. Posteriormente, foram realizados ensaios mecânicos de tração (ASTM D638) e flexão (ASTM D790) nos corpos de prova com e sem tratamentos. Os estudos realizados, mostraram que no ensaio de flexão, o compósito produzido apresentou módulo elástico semelhante à outros compósitos reforçados com fibras lignocelulósicas e além disso aparentou ser um material biodegradável, pois perdeu massa em um período curto de tempo.
\end{abstract}

\section{INTRODUÇÃO}

A busca por materiais poliméricos ecologicamente corretos e que possuem um apelo ambiental vem crescendo cada vez mais dentro da comunidade científica. Os trabalhos de George et al. (2001), mostraram que a conscientização com relação ao desenvolvimento sustentável e ao impacto ambiental se faz presente e aumenta o interesse de pesquisadores na procura de novos materiais oriundos de fontes naturais.

Segundo estudos realizados por Joshi et al. (2004), Martins et al. (2004) e Sena Neto (2014), a produção de compósitos poliméricos utilizando fibras naturais gera vários benefícios como a substituição das fibras artificiais por fibras advindas de fontes renováveis: a diminuição do consumo de energia durante o processamento do polímero e ainda a redução nos custos de produção. Além disso, as fibras lignocelulósicas possuem densidades e custos inferiores às fibras de origem sintética como exemplo, fibra de vidro, fibra de carbono, aramida, boro, entre outras. Na literatura (Martins et al., 2004; Satyanarayna et al., 2009 e Sena Neto, 2014) há exemplos de trabalhos que utilizaram diversas fibras lignocelulósicas 


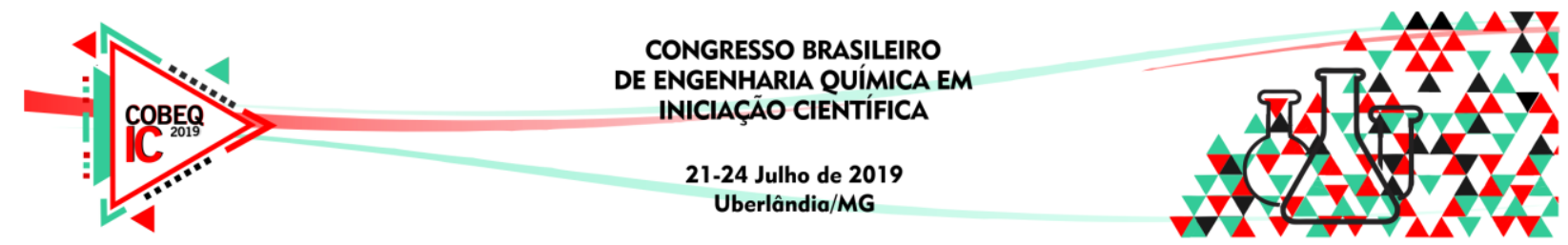

como reforço mecânico em matrizes poliméricas tais como: juta, linho, cânhamo, coco, sisal, algodão e fibra da folha de abacaxizeiro.

A erva-mate Ilex paraguariensis é uma planta originária da América do Sul, consumida no Brasil principalmente em forma de chimarrão, chá mate ou tererê. Segundo dados do IBGE (2013), em 2013 foram produzidas 515.451 toneladas de erva mate no Brasil, assim deve-se considerar que praticamente a mesma quantidade de erva mate produzida, foi descartada na forma de lixo doméstico depois de utilizada. De acordo com estudos realizados por Joshi et al. (2004) e Bourmaud et al. (2013), fibras vegetais como as da erva mate, apresentaram propriedades promissoras quando usadas como reforço em compósitos e aglomerados termoprensados. O material lignocelulósico obteve sucesso quando incorporado a compósitos de polipropileno por termoprensagem, além disso apresenta propriedades físicas e mecânicas de alta performance.

\section{METODOLOGIA}

Amostras do resíduo da erva mate (Ilex paraguariensis) foram obtidas no comércio local de Lavras -MG. Para este projeto, foi utilizado o resíduo da erva mate após sua infusão. O polipropileno reciclado (PP) já na forma de grânulos foi obtido de cooperativas locais de reciclagem de polímeros para ser utilizado como matriz do compósito.

Através de uma extrusora SJSL20 da NZ Philpolymer foram extrudados filamentos do novo compósito, com formulações na proporção mássica do resíduo da erva mate em relação a matriz de PP: $0 \%, 10 \%, 20 \%, 30 \%$, mais uma formulação de $20 \%$ com compatibilizante Bondyram 1001, para avaliar efeitos de interação. Neste mesmo equipamento os filamentos passaram por um processo de peletização para obtenção de grânulos. Com a obtenção dos péletes, foram produzidos corpos de prova de tração (ASTM D638) e flexão (ASTM D790) em uma termoprensa Marconi MA098.

Para ensaio de fotodegradação, utilizou-se em um sistema fechado com ventilação e exaustão adequados, duas lâmpadas UVA (comprimento de onda 320 a 400 ๆm) e uma lâmpada fluorescente. Por meio do ensaio de fotodegradação foi possível quantificar a degradação das amostras termoprensadas por radiação UV. O efeito da fotodegradação foi avaliado através de ensaios de flexão das amostras, após 120 dias de tratamento.

Para a realização do ensaio de biodegradação, corpos de provas de tração foram acondicionados em câmaras incubadoras feitas de material reciclável com dimensões apropriadas e orifícios dispostos na superfície. Com o intuito de simular o ambiente de biodegradação foi utilizado substrato orgânico e para umedecê-la foi criado um próprio compartimento na incubadora que levava a água para o solo por meio da capilaridade. $\mathrm{O}$ efeito da biodegradação nas amostras foi avaliado através de ensaios de tração, após 120 dias de tratamento. Para obtenção de parâmetros, ensaios de flexão e tração foram feitos com amostras que não sofreram nenhum tipo de tratamento físico-químico.

\section{RESULTADOS E DISCUSSÕES}


Figura 1 - Gráfico das curvas tensão-alongamento do ensaio de flexão para todas as formulações sem tratamento.

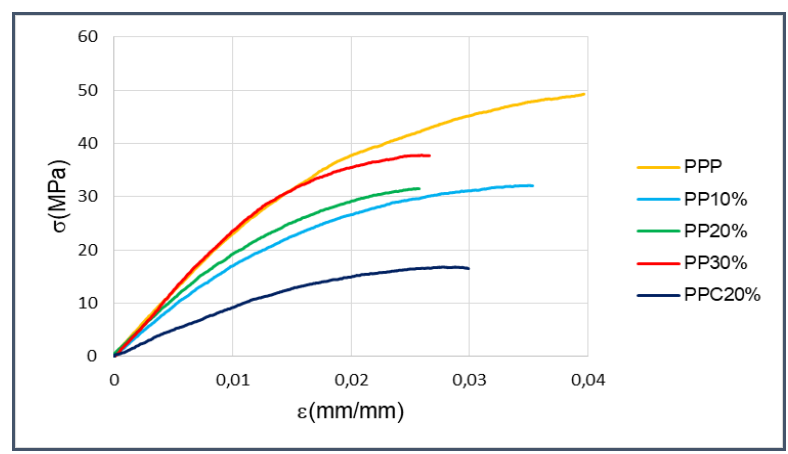

Figura 2 - Gráfico das curvas tensão-alongamento do ensaio de flexão para todas as formulações fotodegradadas no período de 120 dias.

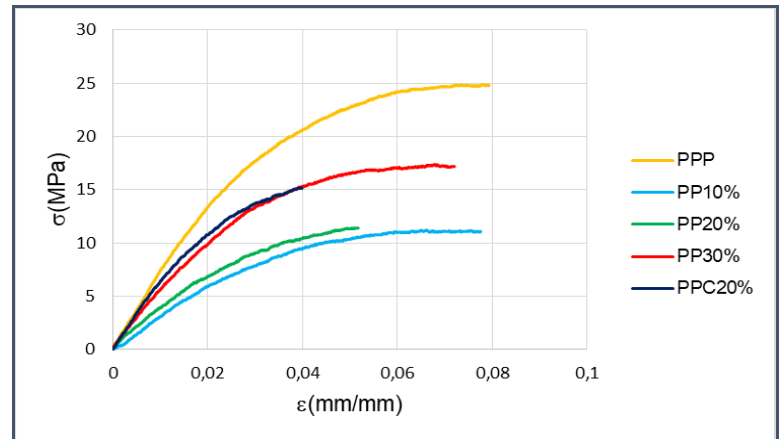

Figura 3 - Gráfico das curvas tensão-alongamento do ensaio de tração para todas as formulações sem tratamento.

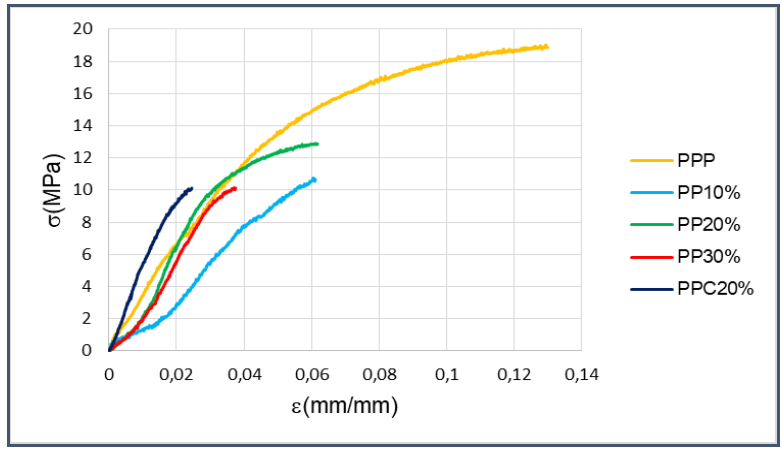




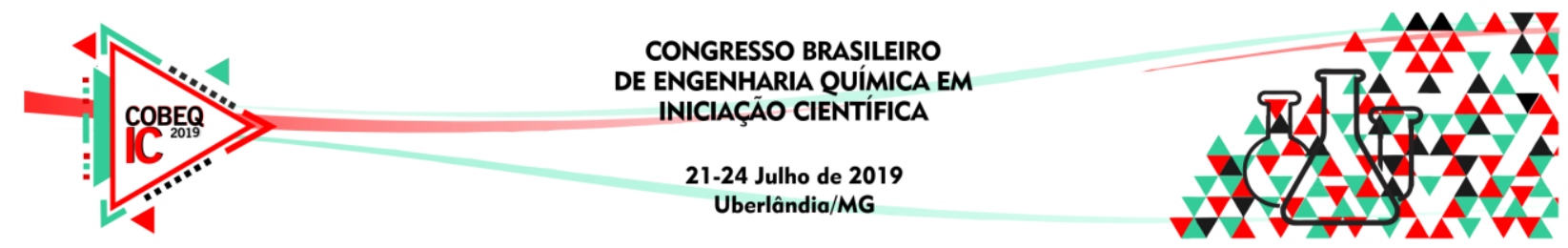

Figura 4 - Gráfico das curvas tensão-alongamento do ensaio de tração para todas as formulações biodegradadas no período de 120 dias.

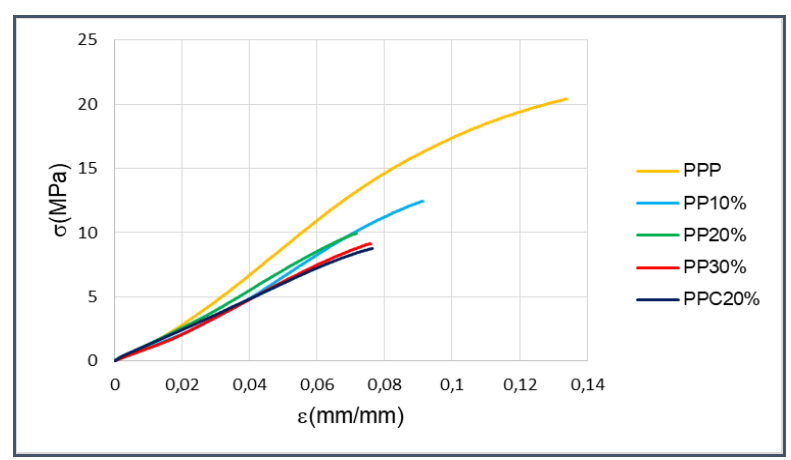

Através do ensaios de flexão, nos corpos de prova sem tratamento, analisou-se três propriedades de interesse - resistência a flexão, alongamento na ruptura e módulo elástico. Através desta análise foi possível perceber que em comparação com o PPP, os compósitos poliméricos de PP10\%, PP20\%, PP30\% e PPC20\%, obtiveram valores inferiores das propriedades mecânicas de interesse.

Quanto as amostras que sofreram fotodegradação durante 60 dias, constatou-se que as propriedades mecânicas não sofreram praticamente nenhuma modificação comparadas àquelas das amostras não fotodegradadas. Ou seja, os valores de resistência a flexão, alongamento na ruptura e módulo elástico se mantiveram semelhantes aos corpos de prova sem tratamento de fotodegradação. Com o intuito de evitar gráficos repetidos das curvas de tensão-alongamento para as amostras com e sem tratamento, neste trabalho foi colocado somente o gráfico da figura 1 (que são das amostras sem tratamento) para representar os dois tipos de experimentos (amostras sem tratamento de fotodegradação e com tratamento de fotodegradação), visto que os resultados foram semelhantes.

Com relação as amostras fotodegradadas durante 4 meses (120 dias), percebeu-se que os valores de resistência a flexão e módulo elástico reduziram na maioria das formulações em mais de 50\%, quando comparadas com as amostras fotodegradadas por 60 dias (ou com as amostras que não sofreram fotodegradação, pois os resultados foram os mesmos). Outro valor a ser considerado, foi o aumento obtido no alongamento na ruptura para todas as formulações deste lote conforme mostra a figura 2.

Nos ensaios mecânicos de tração do lote que não foi submetido ao tratamento de biodegradação (figura 3), foi diagnosticado que o módulo de elasticidade nas formulações de PP10\%, PP20\%, PP30\% e PPC20\% tiveram valores bem próximos do observado na formulação de PPP. Com relação a resistência à tração e alongamento na ruptura, os valores foram decrescendo conforme o aumento da carga vegetal do compósito polimérico.

Por fim, observou-se que nos ensaios de tração realizados nos corpos de prova que sofreram tratamento de biodegradação durante 120 dias (figura 4), o módulo elástico e a resistência à tração diminuíram em praticamente todas as formulações, no entanto, o alongamento na ruptura aumentou em todas as variedades dos compósitos poliméricos. 


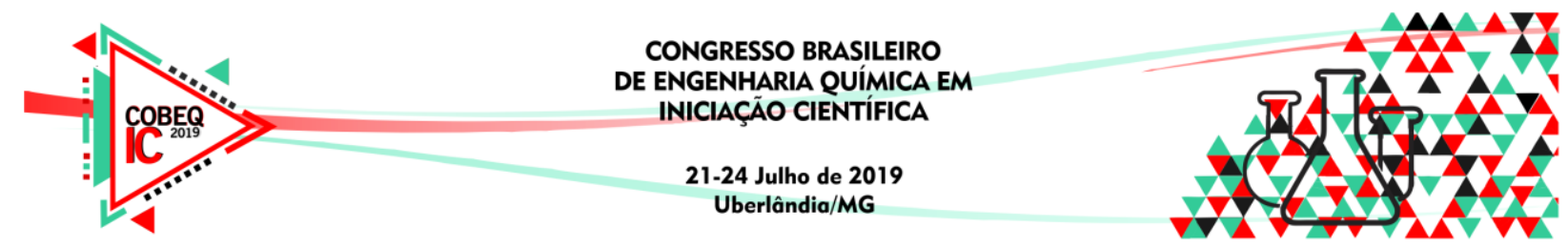

\section{CONCLUSÃO}

No ensaio de flexão de 3 pontos, o módulo elástico de todas as formulações apresentaram valores superiores comparados com outros compósitos da literatura, como compósitos de polipropileno reforçados com fibra de coco verde, e valores semelhantes a outros compósitos, como compósitos de polipropileno reforçados com fibras celulósicas de bagaço e palha da cana de açúcar.

As amostras que sofreram tratamento de fotodegradação durante 120 dias apresentaram, no ensaio de flexão, valores de módulo elástico com decréscimo de mais de $50 \%$ comparado com os valores das amostras sem tratamento. Isso é um indicativo de que as amostras sofreram deterioração por radiação ultravioleta.

A formulação com adição de compatibilizante apresentou propriedades mecânicas semelhantes à formulação que continha a mesma quantidade de resíduo vegetal, porém isenta de compatibilizante em sua formulação. Sendo assim, o compatibilizante não alterou a relação de adesão entre a matriz de PP e a fibra de erva mate e consequentemente não influenciou nas propriedades mecânicas dos compósitos produzidos.

Todas as formulações sem tratamento submetidas ao ensaio de tração apresentaram valores inferiores aos compósitos poliméricos reforçados com fibras vegetais pesquisados na literatura, tais como compósitos de polipropileno reciclado com casca de aveia e compósitos de polipropileno reforçados com fibra de sisal.

As amostras que foram submetidas ao tratamento de biodegradação, posteriormente seguido de ensaio de tração, apresentaram resultados de módulo de elasticidade inferiores àqueles apresentados para as amostras sem tratamento.

No ensaio mecânico de tração das amostras biodegradadas, os resultados decresceram em relação as amostras sem tratamento e isso é um indicativo de que as amostras se degradaram pela ação de micro-organismos presentes no meio em que as amostras foram tratadas.

\section{REFERÊNCIAS}

BOURMAUD A, MORVAN C, BOUALI A, PLACET V, PERRÉ P, BALEY C, Relationships between micro-fibrillar angle, mechanical properties and biochemical composition of flax fibers. Industrial Crops and Products, v. 44, p. 343-351, 2013.

GEORGE J, SREEKALA M S, THOMAS S, A review on interface modification and characterization of natural fiber reinforced plastic composites. Poly. Eng. Sci, v.41, n.9, p.1471-1485, 2001.

IBGE, Instituto Brasileiro de Geografia e Estatística. Censo agropecuário, 2013. 


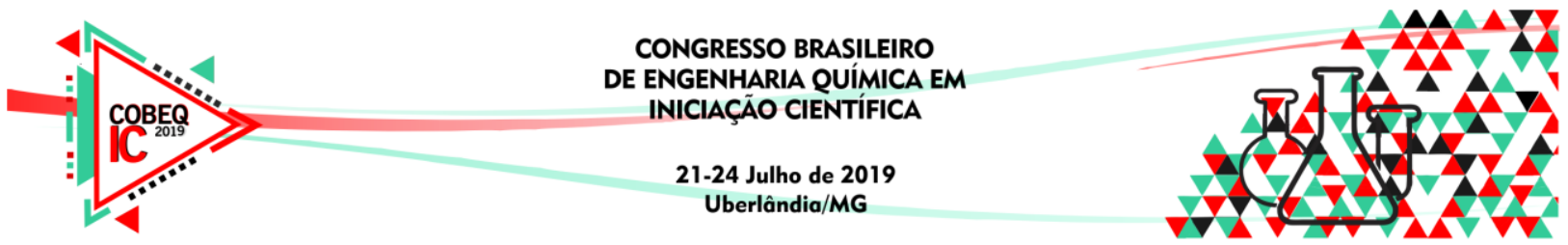

JOSHI S V, DRZAL L T, MOHANTY A K, ARORA S, Are natural fiber composites environmentally superior to glass fiber reinforced composites? Composites Part A: Applied science and manufacturing, v. 35, n. 3, p. 371-376, 2004.

MARTINS M A, KIYOHARA P K, JOEKES I, Scanning electron microscopy study of raw and chemically modified sisal fibers. Journal of applied polymer science, v. 94, n. 6 , p. 2333-2340, 2004.

SATYANARAYANA K G, ARIZAGA G G, WYPYCH F, Biodegradable composites based on lignocellulosic fibers-an overview. Progress in Polymer Science, v. 34, n. 9, p. $982-$ 1021, 2009.

SENA NETO A R, "Estudo de fibras de folhas de abacaxis (gênero ananas) e sua utilização em compósitos biodegradáveis com matriz de poli (ácido láctico) (PLA)”. Programa de Pós-graduação em ciência e engenharia de materiais, UFSCar, 2014. 